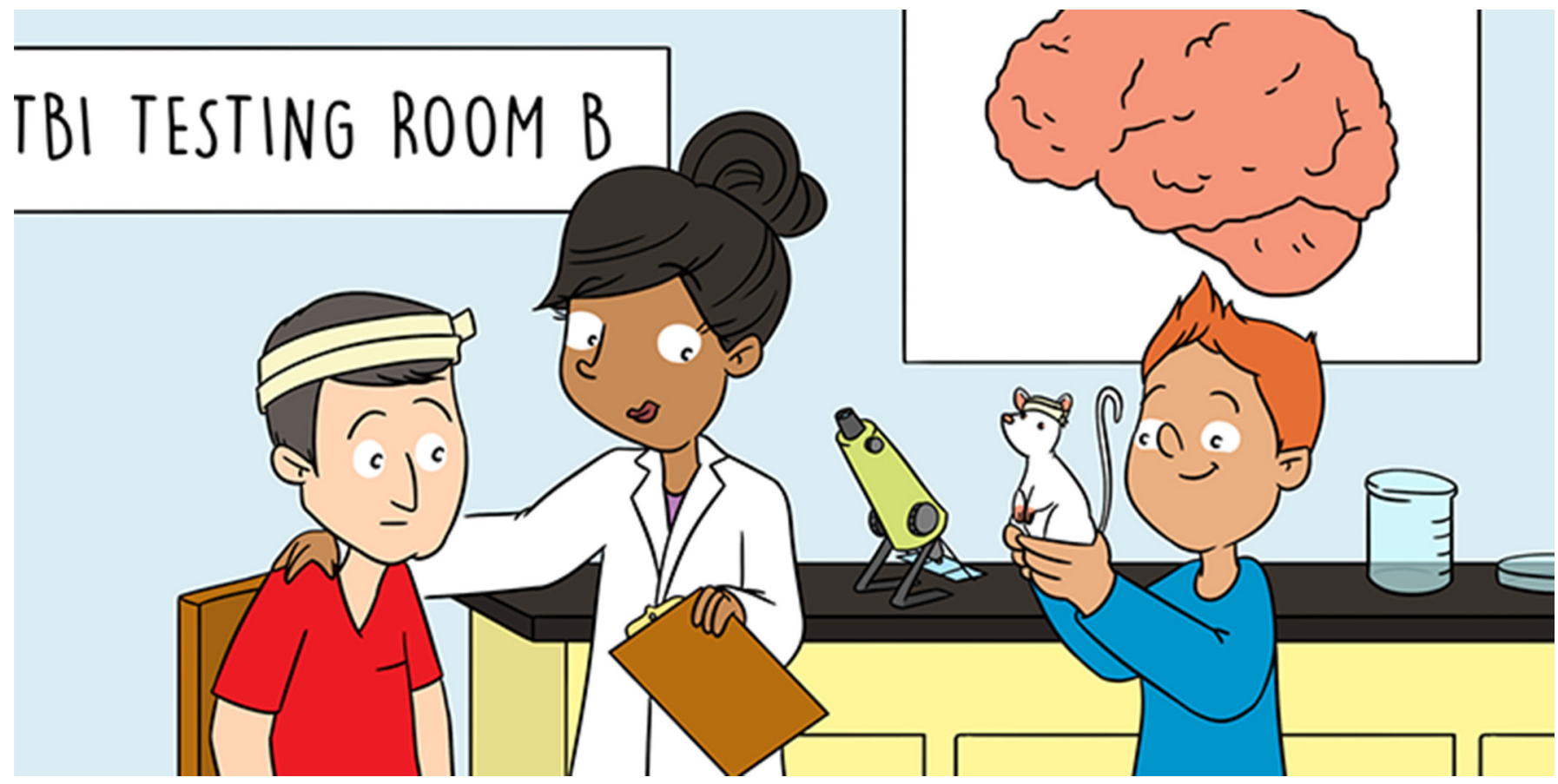

\title{
INVESTIGATING TBI USING ANIMAL MODELS
}

\section{Milin Kurup *, Guriel Kim, Lindsey Morrow, Samuel Ruiz and Kevin K. W. Wang *}

Program for Neurotrauma, Neuroproteomics \& Biomarkers Research, Departments of Emergency Medicine, Psychiatry, Neuroscience and Chemistry, University of Florida, Gainesville, FL, United States

YOUNG REVIEWER:

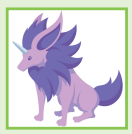

MAXWELL

AGE: 12
In the USA, there are 2.8 million emergency room visits for traumatic brain injury (TBI) each year and about 1.2 million people are living with brain function problems due to TBI. Although much information has been gained from experimental and clinical studies showing how injuries happen, no effective treatments are currently available for TBI. To understand the effects of TBI on the brain and spinal cord, scientists use animal models as a cost-effective research method. Larger animal models, such as pigs or sheep, are closer in bodily functions to humans. However, the use of rodent models is preferred because they are easy to work with in the lab. Importantly, this also fits with the national recommendations to use the lowest mammalian species that can provide the answer to the scientific question. Using rodents, scientists can control specific details, such as the type of brain injury and the severity of the injury. There are ethical concerns about injuring in animals in scientific experiments, but scientists make substantial efforts to ensure the most humane treatment of these animals. Recently, animal models have been used to discover certain proteins, called biomarkers that are present in the brains of people 
TRAUMATIC BRAIN

INJURY (TBI)

Brain damage caused by intense injuries directly targeted to the head, caused by accidents, sports, and other traumas.

\section{CHRONIC}

TRAUMATIC

ENCEPHALOPATHY

(CTE)

Brain deterioration caused by repetitive head injuries, leading to a progressive loss in memory and other brain skills.

\section{TAU PROTEINS}

Proteins present in brain cells called neurons that help the neurons keep their proper structure.

POST-MORTEM

After the death of a patient or subject.

\section{ANIMAL MODEL}

An animal that is used to study the development and progression of a disease and to test new treatments before they are given to humans.

\section{ETHICAL}

Involving questions of right and wrong

\section{with TBI and could lead to the development of new therapies to prevent or reduce disability that can result from TBI.}

\section{WHY DO WE NEED TO UNDERSTAND TBI?}

Traumatic brain injuries (TBIs) are one of the leading causes of injuries and death among people of all ages around the world. Deaths from TBI number in the hundreds of thousands and injuries in the millions. TBls happen to children and adults through automobile accidents, falls, car-vs.-pedestrian injuries, blast injuries in the military, and sports injuries. TBIs can have life-long impacts on the quality of a person's life. Contact sports like football, soccer, boxing, and hockey can result in TBIs. Repetitive head trauma can lead to the development of chronic traumatic encephalopathy (CTE), which is brain deterioration caused by repeated head injuries, leading to a loss of memory and other brain skills. CTE is associated with the accumulation of a substance called tau protein in the brain. CTE begins with mood and impulse-control problems and gradually develops into a devastating loss of brain function, similar to that observed in diseases like Alzheimer's and frontal-temporal dementia. Given that millions of people, including children, engage in contact sports, understanding TBI and CTE is a critical national health issue.

To learn about TBI, scientists would ideally like to study brain tissues from TBI patients. However, brain tissue samples are rarely available form patients. Brain samples from post-mortem (after death) cases of fatal TBI can be studied by scientists, but this is not enough to understand disease processes. Animal models provide a critical method for the study of TBI. Animal models help scientists study and find cures for diseases and disorders that are difficult or not ethical to study in humans $[3,4]$.

\section{WHAT IS AN ANIMAL MODEL?}

Animal models are non-human species which are studied and compared to understand common biological processes. Animal models play an important role in human TBI research. There are many types of animals used in testing. Although larger animals are more similar in bodily processes to humans, rodents are most often used as animal models due to their small size, lower cost, and the fact that it is easy to study multiple small animals in the same experiment. The animals used in TBI research include mice, brown rats, ferrets, and domestic pigs. Some of these animals have brains that are similar to humans and can be used to investigate the mechanisms and potential treatments for human TBI (Figure 1) [4].

In order to make the TBI animal models more like humans, scientists first inject the human tau gene into the animals. Please note that 
Figure 1

This figure shows the anatomy of human, ferret, and mouse brains. Small animals share some structural characteristics with humans and are important in studying $\mathrm{TB}$, even though many animal brains are smaller than human brains. Human brains usually weigh about $1.4 \mathrm{~kg}$, mice/rat brains are $0.002 \mathrm{~kg}$, pig brains are $0.18 \mathrm{~kg}$, cat brains are $0.03 \mathrm{~kg}$, ferret brains are $0.84 \mathrm{~kg}$, and sheep brains are $0.14 \mathrm{~kg}[1,2,5]$.

\section{BIOMARKER}

A molecule that shows whether there is a disease or other problem.

\section{FOCAL INJURY}

Localized tissue damage caused by direct force.

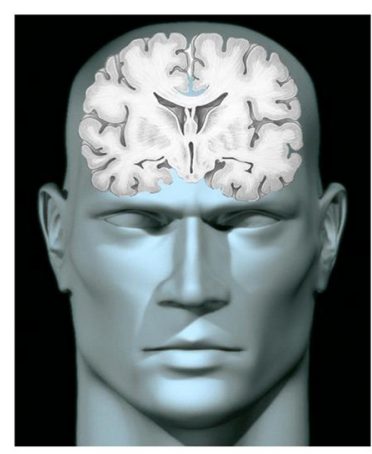

Human Brain

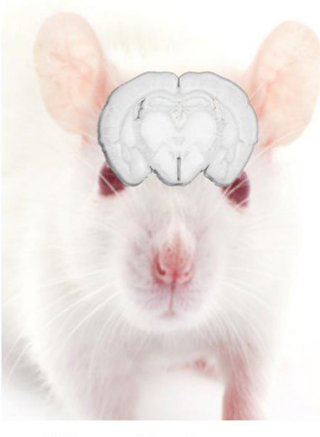

Mouse Brain

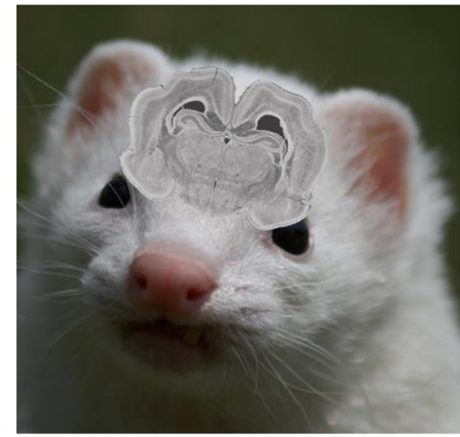

Ferret Brain
Figure 1

all the $\mathrm{TBI}$ research is conducted in anesthetized animals so they do not suffer any pain Then, scientists use different mechanisms to cause TBI in the animals. Unlike in humans where the severity of TBI is uncontrolled, when using animal models scientists have complete control over the type of injury they administer, and they can carefully measure the specific biological and behavioral responses of the animal to the TBI. Scientists use several methods to produce injuries the brain that mimics those that occur to humans. Different TBI models include producing a local injury to the brain, a more widespread injury as might happen in a concussion and a method to induce a blast injury as is often seen in soldiers. As noted, the animals feel no pain since they are under anesthesia and the scientist are safe from any possible injury while they are performing the experiments. After these injuries are administered to the animals, the scientists collect data on the animals' responses over a certain time span and compare them with human patient data $[1,4,5]$.

\section{WHAT DO WE LOOK AT IN THE BRAINS OF ANIMAL MODELS?}

To study $\mathrm{TBI}$, scientists often look at specific brain proteins called biomarkers. Biomarkers are a measure of a disease process, usually measured after focal injury? A typical biomarker would be the level of your blood glucose as a way to monitor diabetes. In $\mathrm{TBI}$, the biomarkers we are interested in including tau proteins, glial fibrillary acidic protein, ubiquitin carboxy-terminal hydrolase L1, neuron-specific enolase. All of these proteins are part of the molecular structures that make up brain cells in both humans and the animal models, like the wood that holds up the framework of a house. When someone goes through a trauma or injury, these brain proteins break apart, resulting in brain cell deterioration, breaking down the framework of the brain. Let us focus on the example of tau proteins. In brain cells called neurons, tau proteins help make up the structure of the long, thin arms of the cells, called axons, which communicate with other neurons. The deposition of tau disrupts 
Figure 2

Tau proteins are like the nails that connect the framework of a wooden house. Tau proteins connect the microscopic parts of brain cells together to create their structure. During TBI, the impact of a hit can cause the tau proteins to react with other chemicals and fall off the structure. These tau fragments collect, and form buildups called tau plaques. These plaques cause a mess around the framework, like a construction mess. Plaques can cause malfunction of the brain and can lead to memory loss, movement issues, and other behavioral changes [4].

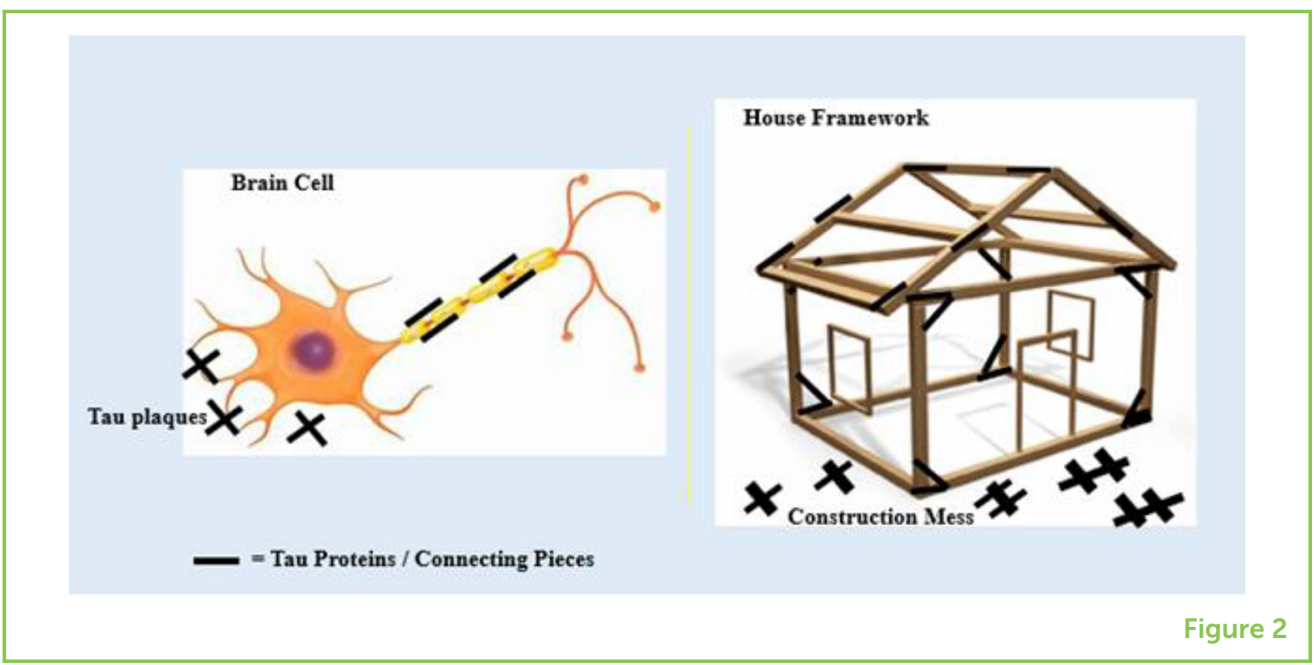

communication between brain cells, which leads to disordered thoughts and behaviors. The buildup of tau leads to memory loss, slow movement, loss of intellect, and other devastating behavioral changes. Similar to tau, all the other proteins listed also build up in the brain in a similar fashion and have similar devasting effects. Scientists have been trying to determine what leads to increases in the formation of these protein deposits and how to limit them (Figure 2) [3, 4].

\section{WHAT ARE THE BENEFITS OF USING ANIMAL MODELS?}

The use of animal models allows researchers to investigate diseases in ways that would be impossible in human patients because of ethical concerns. Humans and animals have similar basic cell processes, so the data collected from animals can reliably predict similar results in humans. Animal research also allows scientists to collect data from many different animals, which increases the reliability of the research findings. Some experimental animals, such as mice, reproduce in very large numbers, so there are lots of mice to use for research.

There is much discussion about whether it is right or wrong to use animals for research. and Some people argue that there is not enough solid evidence to compare animal models to human models. But other people argue that using animals in research is the only way to learn about some human diseases and to find solutions to those diseases. $\mathrm{TBI}$ research, such as the new study on tau biomarkers, helping us detect potentially better diagnosis for concussions, would not have provided a breakthrough in understanding TBI without the use of animal models. Using only post-mortem human samples does not provide enough data to test the scientific theories about the role biomarkers play in TBI. Animal models help us study the human system in faster and more efficient ways. 
Many people fight for the ethical rights of animals, believing that animals should live without the distress of being experimental subjects. To maintain ethical practices, scientists have established regulatory boards to enforce a strict set of rules concerning animal research. There are things scientists can and cannot do, and rules about what types of research animal models can and cannot be used for. These rules support the three R's: replace, reduce, and refine. Scientists must organize their experiments so that they replace animals with other non-animal alternatives as often as possible. In addition, scientists must plan their experiment so that they reduce the number of animals used to the smallest possible number that will give them adequate evidence for their research question. Finally, scientist must refine the procedures done on the animals to reduce excessive harm or I distress to the animals. These rules and regulations allow scientists to get good results with the least consequences for the animals. There have been major breakthroughs in understanding human diseases using animal models, but hopefully, as technology advances, scientists will gradually be able to use fewer and fewer animals for their research $[1,5]$.

\section{CONCLUSION}

Animal models are an essential tool for many types of scientist research. For scientists like us who study the brain, animals help us investigate one of the most complex organs in the body. Animal models help us study key features of diseases that are hard to investigate using human subjects. These models have helped us understand the process by which the buildup of certain proteins, like tau, in the brain damages the brain's structure and function. With this information, scientists are working to discover methods to limit the amount of tau buildup, which in turn could decrease the effects of serious diseases like CTE, Alzheimer's, Parkinson's, and other disabling disorders of the brain.

\section{REFERENCES}

1. Dai, J. X., Ma, Y. B., Le, N. Y., Cao, J., and Wang, Y. 2018. Large animal models of traumatic brain injury. Int. J. Neurosci. 128:243-54. doi: 10.1080/00207454.2017.1380008

2. Rogers, S. 2019. Big Thinkers. Simonrogersdotnet.files.wordpress.com. Available online at: https://simonrogersdotnet.files.wordpress.com/2014/ 03 /brain-size.png (accessed November 4, 2019).

3. Wang, J., Su, E., Wang, H., Guo, C., Lawrence, D. A., and Eitzman, D. T. 2018. Traumatic brain injury leads to accelerated atherosclerosis in apolipoprotein $\mathrm{E}$ deficient mice. Sci. Rep. 8:5639. doi: 10.1038/s41598-018-23959-2

4. Whitwell, J. L., and Josephs, K. A. 2013. "Tauopathies," in Magnetic Resonance Imaging in Movement Disorders: A Guide for Clinicians and Scientists, ed P. Tuite (Cambridge University Press). p. 147-66. doi: 10.1017/CBO9781139207294.014 
5. Xiong, Y., Mahmood, A., and Chopp, M. 2013. Animal models of traumatic brain injury. Nat. Rev. Neurosci. 14:128-42. doi: 10.1038/nrn3407

SUBMITTED: 21 August 2019; ACCEPTED: 11 February 2020;

PUBLISHED ONLINE: 28 February 2020.

EDITED BY: Robert T. Knight, University of California, Berkeley, United States

CITATION: Kurup M, Kim G, Morrow L, Ruiz S and Wang KKW (2020) Investigating TBI Using Animal Models. Front. Young Minds 8:23. doi: 10.3389/frym.2020.00023

CONFLICT OF INTEREST: The authors declare that the research was conducted in the absence of any commercial or financial relationships that could be construed as a potential conflict of interest.

COPYRIGHT () 2020 Kurup, Kim, Morrow, Ruiz and Wang. This is an open-access article distributed under the terms of the Creative Commons Attribution License (CC BY). The use, distribution or reproduction in other forums is permitted, provided the original author(s) and the copyright owner(s) are credited and that the original publication in this journal is cited, in accordance with accepted academic practice. No use, distribution or reproduction is permitted which does not comply with these terms.

\section{YOUNG REVIEWER}

\section{MAXWELL, AGE: 12}

I am interested in a lot of different things and am curious about the world. I am humorous yet I can also be a bit dim at times.

\section{AUTHORS}

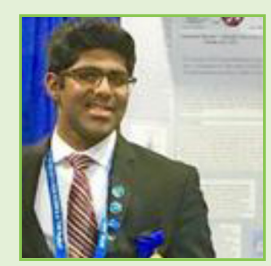

\section{MILIN KURUP}

Milin Kurup is a sophomore studying at the University of Florida, majoring in Microbiology and Cell Sciences. His Principle Investigator, Dr. Kevin Wang, and Ph.D. candidate Hamad Yadikar have been working with him on multiple experiments related to the buildup of tau plaques in the brain for the last 2 years. After experience in neurological research, he hopes to pursue a career in pediatric neurosurgery and hopes to inspire children in medical sciences. *milinkurup@ufl.edu

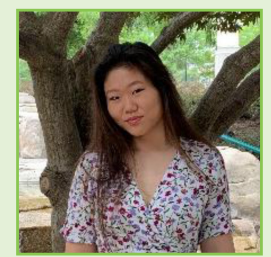

\section{GURIEL KIM}

Guriel Kim is a sophomore studying at the University of Florida, majoring in Health Science and International Studies. She is currently working in Dr. Kevin Wang's lab, doing experiments on samples sent from different companies all around the world. After graduation, she hopes to become a general surgeon with a focus in transplantation surgery. 


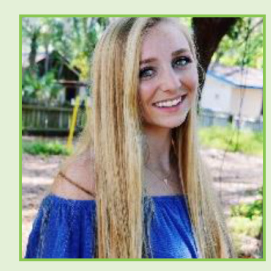

\section{LINDSEY MORROW}

Lindsey Morrow is a sophomore studying at the University of Florida in the University Honors Program majoring in Biochemistry with a minor in Health Disparities in Society. Through Dr. Wang's lab, she is currently on a team that is working on the International Collaboration on Neuroinflammation Project, in which they explore the difference of severities and age ranges of TBI on a molecular level. After graduation she hopes to pursue a career in medicine.

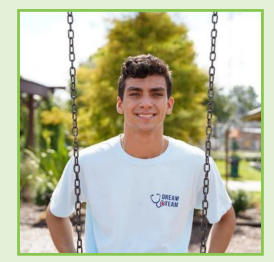

\section{SAMUEL RUIZ}

Samuel Ruiz is a junior at the University of Florida majoring in Biology with a minor in Spanish. He is currently working with Dr. Wang's lab and is working on learning about the biochemical aspects of TBI through the animal model. In addition, he works with a non-profit organization known as Dream Team, where he helps pediatric cardiac patients. In the future, he hopes to become an orthopedic surgeon.

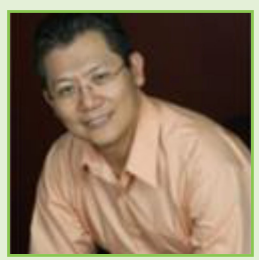

\section{KEVIN K. W. WANG}

Dr. Kevin Wang is the Director of the Program for Neurotrauma, Neuroproteomics \& Biomarkers Research and Associate Professor of Emergency Medicine at the University of Florida and the McKnight Brain Institute in Gainesville, Florida, USA. $\mathrm{He}$ is also Health Research Neuroscientist and Merit Award Principal Investigator at the Brain Rehabilitation Research Center at the Malcom Randall VA Medical Center (Gainesville, FL). *kwang@ufl.edu 